\title{
Using export market performance to evaluate regional preferential policies in China
}

\author{
Annette Schminke · Johannes Van Biesebroeck
}

Published online: 17 January 2013

(C) Kiel Institute 2013

\begin{abstract}
We evaluate the effectiveness of two types of preferential regional policy programs in China's manufacturing sector. The primary goal of the Economic and Technological Development Zones (ETDZs) is to facilitate internationalization strategies, while Science and Technology Industrial Parks (STIPs) aim to generate technology spillovers. Various dimensions of export market performance are used as objective indicators for the upgrading of product quality and firm operations. We compare startups that locate into one of these zones with startups on the outside, while controlling for self-selection using treatment evaluation methods. The results indicate that firms locating in an ETDZ achieve much higher export values, driven by higher volumes of trade and numbers of destinations. Firms locating in a STIP perform best on quality dimensions. In particular they fetch higher export prices and have more success exporting to high-income countries.
\end{abstract}

Keywords Spillovers · International trade - Upgrading · Regional policy

JEL Classification $\mathrm{F} 14 \cdot \mathrm{R} 11 \cdot \mathrm{L} 2$

\section{Introduction}

Preferential regional policies have played an important role in the restructuring of the Chinese economy that started in 1978. Economic and Technological

A. Schminke · J. Van Biesebroeck $(\bowtie)$ University of Leuven, Leuven, Belgium e-mail: jo.vanbiesebroeck@kuleuven.be
A. Schminke
e-mail: annette.schminke@kuleuven.be
J. Van Biesebroeck
CEPR, London, UK 
Development Zones (ETDZs) have as primary goal to facilitate firms' internationalization strategies, while Science and Technology Industrial Parks (STIPs) intend to stimulate technology spillovers. The implicit aim of both types of preferential policy areas is to facilitate firms' movement along an upgrading trajectory from low to higher value added activities.

Our goal is to investigate whether locating in an ETDZ or a STIP is effective in this respect. We compare the performance of manufacturing firms that have chosen to locate in such areas with startups that locate elsewhere. To make sure that the results are informative about firms' upgrading trajectory, we need an appropriate performance criterion. To give the comparison a causal interpretation, we need to account for self-selection into these areas.

In contrast with earlier studies, we do not use research and development (R\&D) expenditures or foreign direct investment (FDI) inflows to measure success of regional policies. They really measure input that might lead to good performance, but no aims that might be pursued. Performing R\&D is even a pre-condition to locate in a STIP and plants financed by FDI are often required to locate in an ETDZ. Productivity directly measures performance, but it relates only imperfectly to the upgrading objective. A firm using a simple production process or producing a basic product can still achieve high productivity if it operates very efficiently.

In this study, we use several dimensions of export market success as performance criteria instead. There is a wealth of evidence demonstrating that the most able firms self-select into the export market (Roberts and Tybout 1997; Wagner 2007). The necessity to overcome fixed or sunk costs of exporting is an important part of the mechanism that generates this correlation. To the extent that accessing each export market entails additional fixed costs (Arkolakis 2010), the number of export destinations provides a further signal of firm quality. Evidence in Hallak (2006) illustrates that richer countries have a higher willingness to pay for quality. The fraction of exports going to high-income countries and the (relative) price a firm receives on international markets are additional indicators of success.

We cannot ignore the endogenous nature of firms' location decision. Locating in a STIP or an ETDZ might very well be more advantageous for firms that would have performed better than average anywhere. If this is the case, self-selection into these areas would result in upwardly biased estimates of the causal effects on performance.

In the terminology of the Rubin Causal Model, we need to find an estimate for the potential performance of 'treated' firms, i.e.firms that locate in a preferential area, had they located elsewhere. This counterfactual is inherently unobservable, but we implement two estimators from the literature on the evaluation of treatment effects, recently reviewed in Imbens and Wooldridge (2009). Exploiting the unconfoundedness and overlap assumptions, we construct an appropriate benchmark from the performance of untreated firms that are similar in observable characteristics. We only focus on new entrants which reduces the size of the sample substantially, but avoids diluting the comparison by unobservable firm histories. Pre-selecting on export status also makes the treatment and control groups more comparable. 
Previewing some of the results, we find that firms locating in both types of preferential area are more successful exporters, measured by total value. The effect is largest and most robust for STIPs which can be attributed to the much higher prices that these firms fetch on the export market compared to control firms and even compared to firms in ETDZs. The price premiums are particularly pronounced for firms producing machinery and electronic equipment. In addition, firms in STIPs sell a significantly higher share of their exports in high-income countries.

A similar strong export performance of firms in ETDZs, in terms of total value, barely shows up in their export prices. Even the highest point estimates are only significant at the $10 \%$ level and they are an order of magnitude smaller than for STIPs. In contrast, there is some evidence that firms in ETDZs are able to reach a larger number of export destinations. This effect is most pronounced for domestic firms. In summary, one could say that the export performance of firms in STIPs excels in the quality dimension, while firms in ETDZs perform better in the quantity dimension.

A few studies have previously evaluated the effects of these preferential policy areas. $\mathrm{Hu}$ (2005) documents the overall positive contribution of ETDZs to the local economy, notably in terms of attracting FDI, but no effort is made to control for confounding factors. Démurger et al. (2002) stress in particular that one should control for location within China before attributing an effect to a preferential zone. Based on interviews and self-collected information for STIPs and other science parks, Walcott (2003) is sceptical that proximity of firms fosters 'innovationpromoting learning.' She finds that multinational companies often use China only as assembly base which limits the potential for technology transfer and skill enhancement for Chinese employees. Additional studies are discussed in the next section.

Focusing specifically on STIPs, two systematic empirical studies fail to find consistent benefits. Hu (2007) finds evidence of labor productivity convergence across different STIPs, but no evidence of local externalities from geographically concentrating high-tech firms. STIPs contribute to economic growth within their region, but not enough to reverse the secular trend of rising regional inequality. Zhang and Sonobe (2011) find positive agglomeration effects for the presence of high-tech firms, FDI, and research activity of academic institutions, but these spillover benefits even accrue to firms in the same city but outside the parks. At the same time, congestion effects within STIPs depress productivity for firms inside the park.

An important drawback of all previous studies is the lack of comprehensive firmlevel data. They rely on case studies or information at the regional level, broken down between on-park and off-park firms. Hu (2007) further conjectures that it might have been too early to assess the full potential of technology parks as his sample only covers the 1992-2000 period. Finally, none of the studies control for the self-selection of firms into the preferential areas. We remedy all three problems to some extent.

The remainder of the paper is organized as follows. In Sect. 2, we describe the development and organization of the preferential policy areas in China. In Sect. 3 we outline our empirical strategy to control for firms self-selecting into these areas. 
The data is described in Sect. 4, followed by the estimation results in Sect. 5. We close with conclusions on firm behavior and policy in Sect. 6.

\section{Overview of preferential policies}

2.1 Economic and technological development zones as part of the 'open door' policy

Even though the Chinese economic reforms in 1978 started in the agriculture sector, from the beginning three Special Economic Zones were created in Guangdong in 1979 followed by a fourth one in Fujian the next year. The first ETDZs were created after Deng Xiaoping's first southern tour in 1984. Together with the Coastal Open Cities initiative, they were added to the policy portfolio to expand the preferential policy environment to additional areas.

Over the 1984-2002 period a total of 54 ETDZs were established. Initially, they were limited to coastal provinces and specifically set up in rural areas to isolate them from the rest of the economy (Liu and $\mathrm{Wu}$ 2011). After Deng's second southern tour in 1992 a second wave of ETDZs was established, extending the policy to Central and Western regions. The establishment of the final wave in 2000-2002 coincided with China's entry into the World Trade Organization.

Like the original Special Economic Zones their primary aim was to help the Chinese manufacturing sector integrate in the global economy. Cornerstones of the policy were duty-free imports for dedicated exporters and less restrictive entry regulations for foreign multinationals-hence their label 'preferential' policy areas. Projects funded with FDI were initially forced and later encouraged to locate in these dedicated areas. ETDZs invariably show a high concentration of multinational corporations and are not devoted to specific industries, in contrast with STIPs.

Firms that located in an ETDZ receive tax holidays or reduced rates on various taxes. Those that produce solely for the export market are exempt from import tariffs on intermediate inputs and machinery and they are automatically awarded an export license. Concentrating these firms in a few areas facilitated the logistics of separating the flow of duty-exempt imports from regular imports. It also helped monitoring that duty-free imports did not leak into the wider economy and that outputs actually left the country.

As the export processing sector grew, it gradually became a virtual sector, not tied to specific geographic areas. In all major coastal port cities 'bonded areas' were established to facilitate duty-free importing by qualified exporters (Démurger et al. 2002). Over time, export processing firms were allowed to locate outside ETDZs as well and eventually they could even produce for the domestic market from the same production facilities. Compliance with the trade regime, including the assessment of import tariffs due, was monitored on-site by customs officials using company accounts and occasional inspections. This evolution allowed the exploitation of scale economies in production and diminished local constraints on land and skilled workers in the zones. 
An enduring advantage of the geographically concentrated ETDZs is the possibility of localized externalities. A few recent studies have used sophisticated identification strategies to demonstrate that manufacturing firms are able to learn from successful neighbors, see Swenson (2008) for an application in China and Greenstone et al. (2010) for the United States. The continued popularity of ETDZs is an indication that firms must still derive some benefits from locating there.

Direct evidence on the effectiveness of ETDZs to improve firm performance is very limited. Hu (2005) highlights a positive contribution to the economy, in terms of GDP per capita and the attraction of FDI, but without any benchmark. Liu and $\mathrm{Wu}$ (2011) show that ETDZs accounted for 21.6 and $15.8 \%$ of China's total FDI and trade by 2005, even though they covered only one hundred of 1 of the total territory. The quantification of benefits is complicated by self-selection, dynamic effects, and confounding effects of STIPs, which we discuss next.

\subsection{Science and technology industrial parks and other aspects of innovation policy}

As the Chinese economy developed and achieved export success, sustainable growth became a more prominent objective. Rising labor costs and environmental degradation provided further motivation for policies that would stimulate manufacturing firms to upgrade along the value chain.

Chinese research institutions were originally focused on heavy industries, space technology, mining, and national defense. An early effort in 1982, the 'Key Technologies R\&D Program', promoted technology transfers from research institutes to enterprises. Researchers from universities and state-owned research institutions were also encouraged to found spin-offs (Fan and Watanabe 2006). In 1988, the central government established the Torch Program to generate more economic benefits from the national innovation system.

The Torch Program had four major objectives: (1) improve the support system for high-tech industrialization, (2) foster growth of and enhance innovation in technology-based small and medium sized enterprises (SMEs), (3) improve mobility of factor inputs, especially human capital, and (4) set up technology zones (Hu and Jefferson 2008; Ministry of Science and Technology 2011). An implicit goal was to close the gap with Western economies in industries that produced for private consumption.

The policies proved successful and an important cluster of high-tech firms developed in Zhongguancun Street in Beijing close to Tsinghua University (Saxenian 2002). The State Council officially launched the first STIP, the 'Beijing New Technology Industry Experiment Zone', at this site in May 1988, which was renamed as 'Zhongguancun Science Park' in 1999. The Ministry of Science and Technology established a further 53 parks between 1988 and 2007. Figure 1 illustrates that STIPs are distributed across the entire country with some aggregation in the Beijing, Shanghai, and Shenzhen areas. The Urumqi State High-tech Industrial Development Zone marks the only STIP in the far west of the country.

The STIPs aim to support SMEs in high-tech industries and increase their international competitiveness. They place a strong emphasis on commercial R\&D 


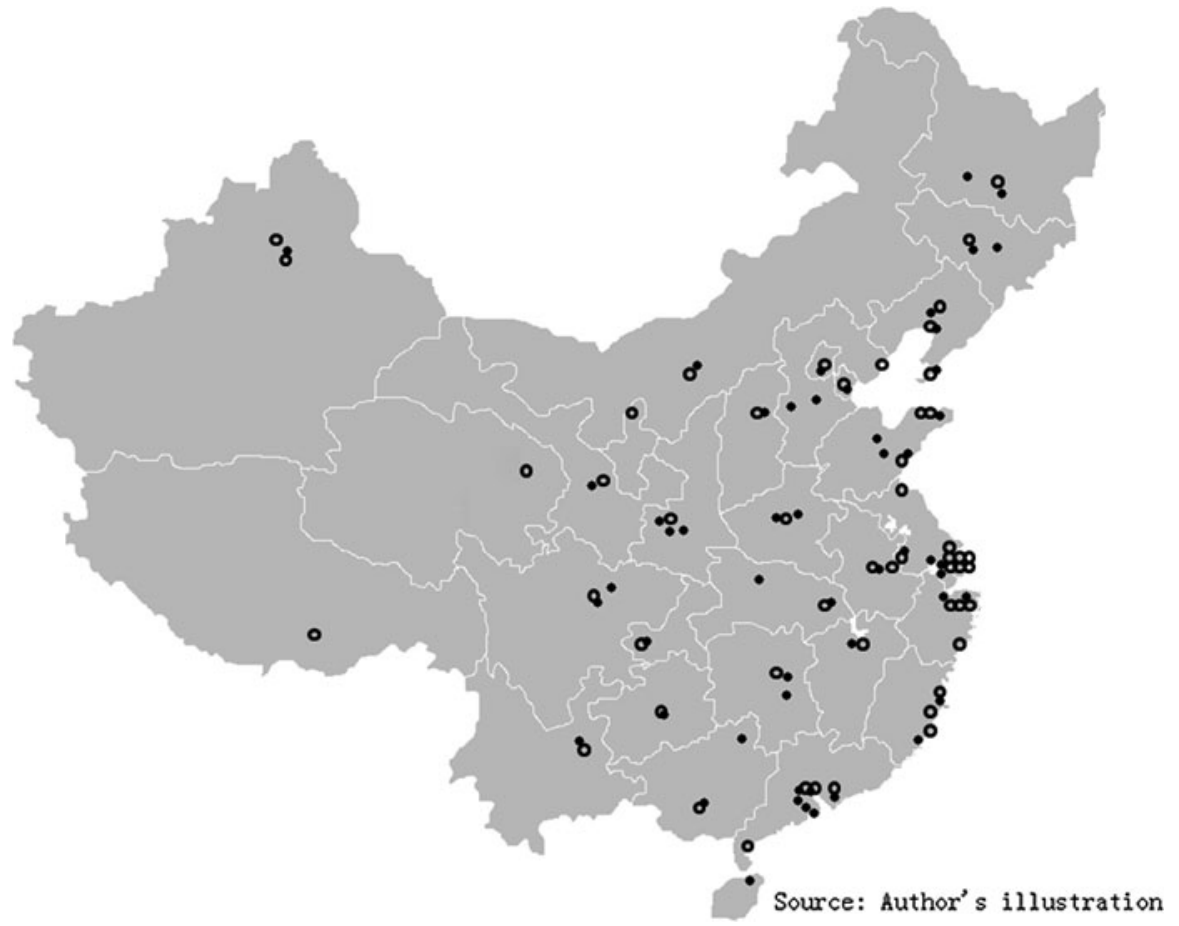

Fig. 1 Geographical distribution of the 54 STIPs (filled circle) and 54 ETDZs (open circle)

and encourage independent innovation, in contrast with more centralized, failed attempts in the 1970s. On-park firms are given preferential treatment on various dimensions, including state-of-the-art infrastructure, lighter regulatory burdens, lower rates of corporate income tax, exemption of import tariffs and export licenses, and rebates for investments (Liu and $\mathrm{Wu} 2011$ ). Local governments are in charge of organizing the parks, but the central government's State Council decides the implementation of development zones and provides the tax holidays.

To locate in a STIP, a firm needs to be certified as 'high-tech' which involves three criteria (Zhang and Sonobe 2011). It must use or develop products, services, or technologies mentioned in the Catalog for High and New Technology Products of the Ministry of Science and Technology. It must invest at least $3 \%$ of its annual gross revenue in R\&D related activities. At least $30 \%$ of its employees must hold a tertiary-level degree and $10 \%$ of its workforce must be employed in the R\&D department. Every year, a provincial government agency in charge of science and technology policies re-evaluates whether the firm still satisfies the three requirements.

One objective of the STIPs is to facilitate knowledge transfers from multinationals to domestic firms. Walcott (2003) finds only limited learning in case studies of seven technology parks of different types (Multinational Development Zones, Multinational Learning Zones, and Innovation Learning Zones). Macdonald and Deng (2004) also express a critical point of view, but no evidence, arguing that the 
majority of STIPs are science parks only in name. In contrast, Inkpen and Wang (2006) do find evidence of technological knowledge transfers in the Suzhou Industrial Park which is an explicit collaboration between the Chinese and Singapore governments. Managerial knowledge, however, was found to be particularly difficult to transfer.

Other studies have compared the Chinese STIPs to similar policies in other countries. In a comparison with Japanese industrial policy, Fan and Watanabe (2006) stress the importance of balancing the import of foreign technology and domestic development and the key role of the private sector in enhancing technological capabilities. Saxenian (2002) examines whether government policies can help transform a brain drain into a 'brain circulation' by giving incentives to Chinese graduates in Silicon Valley to return and start high-tech firms in China. Specially for them, Returning Students Science Parks were created in some existing STIPs. ${ }^{1}$

\section{Empirical methodology}

\subsection{Challenges to evaluate the effects of preferential policy areas}

To evaluate the effects of preferential policies we face a number of challenges. We discuss, in turn, the confounding effects of regional development, the presence of other preferential areas in a region, and the difficulty of establishing an appropriate benchmark. We indicate for each issue how we deal with it in the empirical analysis.

Démurger et al. (2002) stress the importance of controlling for location within China before ascribing effects to a particular preferential policy area. The disparities in regional growth rates and levels of development are too great to overlook. The previously mentioned evidence in $\mathrm{Hu}$ (2007) underscores this fact: he finds positive effects of STIPs, but they are dominated by regional trends. In all regressions we include several location indicators.

Head and Ries (1996) illustrate an additional location effect. Evaluating the early preferential policy areas that preceded the ones we study, they estimate static and dynamic effects on the ability to attract FDI. Their results depend notably on whether the effect of early FDI on the attractiveness of a location for future FDI is taken into account or not. Endogenous location decisions turn out to have a strong magnification effect on agglomeration externalities.

Liu and Wu (2011) document a different type of externality. They show that the two types of areas are complementary, especially in the coastal areas. The effectiveness of an ETDZ in attracting FDI is boosted by the presence of a STIP in the same city. From Fig. 1 it is clear that many locations host both types of preferential policy areas. Therefore, when evaluating the performance of firms in an ETDZ, we always control for the presence of a STIP in the same city and vice versa.

This problem is widespread as many different types of preferential or incentive areas have been established in China. In addition to the early Special Economic

\footnotetext{
${ }^{1}$ For example, Saxenian (2002) identifies 48 companies run by returning students in the Zhongguancun Science Park in Beijing.
} 
Zones and Open Coastal Cities, other geographically concentrated initiatives include Open Coastal Belts, Open Economic Coastal Areas, Open Delta Economic Zones, and Border Economic Cooperation Zones. ${ }^{2}$ In addition to the national (so-called state-level) ETDZs and STIPs with uniform policies, provincial variants exist for both types of areas. We do not include them in our study as they have idiosyncratic policy differences, but their ubiquity makes it particularly valuable to work with firm-level data. Only then is it possible to ascertain carefully which observations are treated. ${ }^{3}$

An important aim of the STIP policy is to pool high-skilled labor markets and to facilitate productivity and knowledge spillovers by agglomerating high-tech firms and R\&D activities. To some extent these objectives also apply to ETDZs which in addition focus on knowledge transfers from multinational firms through FDI. The policy environment of the two types of preferential areas show many similarities (Saxenian 2002), but locating in a STIP is a lot more restrictive. A randomly selected firm is likely to be a much worse benchmark for firms in a STIP than for firms in an ETDZ. It is important to carefully construct an appropriate benchmark and we describe this process in the next section.

\subsection{The treatment effects framework}

Our objective is to investigate the effect of locating in an ETDZ or a STIP on various dimensions of export performance. The main identification problem we face is that we cannot observe what the performance of a 'treated' firm, i.e. one locating in a preferential policy area, would have been if it had chosen to locate elsewhere. If treatment is not random, it would not be appropriate to simply use the performance of firms outside the areas as a benchmark.

Because a firm only selects its location once, we cannot compare changes in performance before and after treatment and use a difference-in-differences approach. Instead, we use two estimators from the treatment effects literature to control for self-selection into treatment. Good overviews of the different methods are provided in Imbens and Wooldridge (2009) and Wooldridge (2010). Note that it is not the endogeneity of the location decision itself that is problematic, but the correlation between this decision and the potential performance in the absence of treatment. We discuss how we break this correlation.

Denote the outcome variable of interest by $y$ and the binary treatment variable by $w$. We follow the Rubin Causal Model and specify two potential outcomes explicitly even though only one is observable for each firm. If unit $i$ is treated its potential outcome is $y_{i 1}$, while it is $y_{i 0}$ if the same unit $i$ is not treated. The assumptions needed for identification can then be specified directly on these objects, separately from the process that governs the selection into treatment.

\footnotetext{
${ }^{2}$ Head and Ries (1996) and Démurger et al. (2002) provide additional information on them.

${ }^{3}$ The use of information on treatment at the firm level has improved the accuracy of similar analyses in other contexts, see for example Hussinger (2008) for an application to R\&D subsidies and Van Biesebroeck et al. (2011) for export promotion.
} 
The average treatment effect (ATE) measures the expected effect of treatment on a random sample of the population or the average effect over the entire population. Because many firms might have no interest in locating in an ETDZ and the majority of firms would not even qualify to locate in a STIP, we are primarily interested in the effect of the program on those who actually participated, i.e. the average treatment effect on the treated (ATT). ${ }^{4}$ We can define it as follows,

$$
\tau_{a t t} \equiv \mathrm{E}\left(y_{1}-y_{0} \mid w=1\right) \text {. }
$$

We rely on two identifying assumptions to deal with the missing information on $y_{0}$ for treated firms. Unconfoundedness, or ignorability of treatment, assumes that once we condition on a sufficiently rich set of covariates $\mathbf{x}$, treatment assignment is essentially randomized Wooldridge (2010). Self-selection into treatment might still be based on unobservables, but only if these are not correlated with potential performance differences after conditioning on the covariates. This clearly is a tall order, and fundamentally untestable because the counterfactual outcome can never be observed. In the absence of (quasi-)experimental assignment, it is the only way forward. In situations where firms self-select during their lifespan and we observe performance before and after treatment, one can relax the unconfoundedness assumption by only making it on the time-differenced performance measures. ${ }^{5}$ Unfortunately, this is impossible for the location decision. Formally, the assumption is expressed as

\section{Assumption $1 \quad\left(y_{0}, y_{1}\right) \perp w \mid \mathbf{x}$.}

The covariates in $\mathbf{x}$ should be effective in breaking the correlation between a firm's potential performance without treatment and the actual treatment decision. Observable characteristics that enter the official rules or that are taken into consideration in the implicit selection process for eligibility to locate in a STIP or ETDZ are effective sources of variation. We include a full set of dummies for the sector, ownership type, and location of the firm, and the year of establishment. Two continuous variables, the average remuneration per employee and the log of employment, are included both linearly and squared. It is important to note that all control and treatment firms are already pre-selected on a positive export status. As exporters are known to exhibit above average performance on many dimensions (Bernard and Jensen 1995), this already makes the two groups of firms more comparable.

In practice, we rely on a weaker version of Assumption 1-mean-independence-which only implies $E\left[y_{0} \mid \mathbf{x}, w\right]=E\left[y_{0} \mid \mathbf{x}\right]$. The law of iterated expectations directly allows the calculation of ATT from (1) conditioning on $\mathbf{x}$. Given our interest in ATT, we then take the sample average of this set of conditional differences over the $\mathbf{x}$ covariates for the sub-sample of treated firms. The calculation of ATE effects starts from the same conditional differences, but averages them over the distribution of covariates for the full sample.

\footnotetext{
${ }^{4}$ Many evaluations of programs with voluntary participation focus on the ATT effect. When treatment is randomly assigned, the ATE equals the ATT.

5 That scenario allows selection into treatment based on time-invariant firm-specific unobservables, see Van Biesebroeck et al. (2011) for an application to the evaluation of export promotion programs.
} 
The second assumption we require is overlap: conditioning on a set of covariates $\mathbf{x}$, each unit in the population may potentially enjoy treatment. Formally:

Assumption $2 \forall \mathbf{x} \in \mathcal{X}, \quad 0<\mathrm{P}(w=1 \mid \mathbf{x})<1$,

where $\mathcal{X}$ is the support of the covariates. If the assumption is satisfied, it guarantees that for each treated firm in the sample we observe some non-treated, control firms with similar covariates. In our application there are far more control than treated firms, which makes this assumption not very demanding. Moreover, we can test whether it is satisfied.

\subsection{Estimating the average treatment effects}

The sample estimator for the ATT is defined as

$$
\hat{\tau}_{a t t}=\frac{1}{\sum_{i} w_{i}} \sum_{i=1}^{N} w_{i}\left[\hat{m}_{1}\left(\mathbf{x}_{i}\right)-\hat{m}_{0}\left(\mathbf{x}_{i}\right)\right],
$$

where the functions $\hat{m}_{1}($.$) and \hat{m}_{0}($.$) are the predicted values of the performance$ variable for treated and untreated firms using the same set of covariates $\mathbf{x}$, but allowing for different coefficients. We can estimate both $m_{i}$ (.) functions at the same time from the following OLS regression

$$
y_{i}=\beta_{1} \mathbf{x}_{i}+\beta_{2}\left(\mathbf{x}_{i}-\overline{\mathbf{x}}_{1}\right) * w_{i}+\tau_{a t t} w_{i}+\varepsilon_{i} .
$$

Because the covariates in the interaction term are normalized by $\overline{\mathbf{x}}_{1}$, the sample means for the group of treated firms, the coefficient on the uninteracted treatment dummy immediately gives the ATT estimate. The only change to estimate the ATE, which we do at the end for the ETDZ effect, is to normalize by $\overline{\mathbf{x}}$ which is averaged over the full sample.

As a robustness check, we implement a second estimator. This approach originated with Robins et al. (1995) and combines the regression adjustment with propensity score weighting. It does not require the specification in (3) to fit the entire covariate-space equally well. The control firms receive a regression weight that is increasing in their probability of treatment. Compared to matching estimators that explicitly match each treated firm to one or several control firms, it is more robust to misspecification of the treatment selection equation. Imbens and Wooldridge (2009) point out that the estimator is consistent as long as the parametric model for either the propensity score or the regression function is specified correctly. Therefore it is said to be double robust.

We implement the double robust estimator using the two-step approach of Hirano et al. (2003). First, we estimate the probability of treatment as a function of the covariates and calculate the predicted value, the propensity score $\hat{p}(\mathbf{x})$. Second, we rely again on Eq. (3) to estimate $\tau_{a t t}$, but now we use the following weights ${ }^{6}$

\footnotetext{
6 To estimate the ATE, the appropriate weights are the inverse probability of treatment or non-treatment for each observation: $\lambda_{i}^{\text {ate }}=w_{i} / \hat{p}\left(\mathbf{x}_{i}\right)+\left(1-w_{i}\right) /\left(1-\hat{p}\left(\mathbf{x}_{i}\right)\right)$.
} 


$$
\lambda_{i}^{a t t}=w_{i}+\left(1-w_{i}\right) \frac{\hat{p}\left(\mathbf{x}_{i}\right)}{1-\hat{p}\left(\mathbf{x}_{i}\right)} .
$$

The parameter of interest is again the coefficient on the uninteracted treatment dummy. Given the two-step procedure, we need to bootstrap the procedure to calculate standard errors.

This estimator requires a distributional assumption on the error term in the treatment selection equation that underlies estimation of the propensity score. The probit estimation we use, assumes the normal distribution. As an alternative we have experimented with the logit functional form and complementary log-log specification that often fits better in samples where treatment is very rare. The pairwise correlation between the implied propensity scores for any two of the three alternatives always exceeds 0.992 , leading to virtually identical ATT estimates.

\section{Data}

We now discuss our two data sources, the sample, and variable definitions. The first data set contains the universe of trade transactions from the Chinese Customs Office for the period 2000-2006 and has only been used in a few studies, e.g. in Manova and Zhang (2012). For each firm-year observation it contains all export transactions at the 8-digit HS product level and by export destination. ${ }^{7}$ Exports are reported in value and quantity (with an indication of units) and we can follow firms over time using a unique identifier. From this information we construct four export performance variables.

The total value of exports and total number of export destinations are defined straightforwardly. The third variable is the share of a firm's exports that go to highincome destinations, following the World Bank (2011) country classification. We calculate this ratio both in number of transactions and in value. The fourth performance variable is the price that a firm fetches on the export market. We divide export values and quantities at the most detailed product level and normalize these unit value ratios by the median value for the product (across all firms and destinations in the same year). They are then aggregated using value shares over all product-destination pairs served by the firm in that year. We also construct an alternative price measure by normalizing the unit value ratios within each productdestination category before aggregating to the firm level. This alternative price does not depend on the composition of trading partners if prices differ systematically by destination.

The second source of information is the annual census of 'above-scale' manufacturing firms from China's National Bureau of Statistics. This data set is already widely used, see Brandt et al. (2012b) for a detailed description. It contains all firms that are state-owned or have annual sales above 5 million RMBapproximately $\$ 600,000$ during the sample period. Unfortunately this excludes the

\footnotetext{
7 Transactions are broken down by month and type of trade (export processing or ordinary trade), but we aggregate over these two dimensions.
} 
smallest private firms that might have located in a STIP. Given that we only use exporters in the analysis, which tend to be larger, we only miss the far left tail. The firm-level data is a panel spanning the 1998-2008 period, which is longer than the period for which we observe export performance information.

From this data set we construct the covariates to control for the selection into treatment. The 2-digit CIC industry classification provides a set of 29 sector dummies. We work at this level of aggregation to avoid problems with the changes in the classification in 2003 and to preserve degrees of freedom. The detailed ownership classification is aggregated into five types: state-owned, collective, private, foreign, and firms from Hong Kong, Macau and Taiwan. The location information is collapsed into a single dummy variable for the Western and Central region, while firms in the coastal provinces are classified in three groups based on proximity to the most important industrial center (Beijing/Tianjin, Shanghai, or Guangdong). ${ }^{8}$ Firm size is measured by the logarithm of the number of employees and the average remuneration per employee includes both wages and non-wage benefits. Each firm reports its startup year.

Firms in the two data sets are matched using a probabilistic matching algorithm based on name, address, sector, and size category; Brandt et al. (2012a) has further details. In the first year (2000), the matched firms account for approximately $42 \%$ of exports. Coverage grows to almost $65 \%$ in the final year (2006) as more firms export directly rather than through trade intermediaries and because the coverage of the firm-level data set improved after the 2004 census. $^{9}$

The final task is to identify 'treated' firms. Two text-variables in the transaction data, the origin of a transaction and the address of the exporter, provide sufficient information to determine whether a firm in a certain city is located inside a STIP or ETDZ. ${ }^{10}$ Given the dynamism and rapid growth of the Chinese economy, we want to avoid that past and unobservable histories contaminated the comparisons. Therefore, we only retained new entrants in both the treated and control groups. Entrants are defined as firms that first appear in the data set in 1999 or later, and report a startup date at most 2 years prior to their first appearance.

We observe a total of 14,110 firms in the control group, 458 firms have chosen to locate in a STIP, and 891 in an ETDZ. The low share of treated firms makes it easy to satisfy the overlap assumption. Descriptive statistics for the final sample, broken down by treatment status, are reported in Table 6 in the Appendix. The high fraction of foreign-owned firms in both areas is notable. This is partly the result of preselecting on export status. STIP firms are more likely to produce machinery and electronics, which is as expected. They also show better than average export

\footnotetext{
${ }^{8}$ We initially used separate dummies for the Western and Central regions, but these gave problems with the balancing test. Even combined they only account for $6 \%$ of firms in the sample.

${ }^{9}$ This coverage ratio is almost as high as in the data set for the United States used in Bernard et al. (2007).

${ }^{10}$ The full list of STIPs is provided on the Web site of the Torch Program Ministry of Science and Technology (2011) and Liu and Wu (2011) provide the complete list of cities with an ETDZ. The firm address information including street name, zip code, and city. For the limited set of cities with a STIP or ETDZ we text-searched the address and origin fields for the Chinese characters that uniquely identify the parks or zones.
} 
performance, underscoring the importance of constructing an appropriate benchmark.

\section{Empirical results}

\subsection{Productivity, capital intensity, and value added}

After the detailed discussion of our objective, approach, and identification strategy, presenting the results is relatively straightforward. We use performance indicators from the firms' second and third years of operation and covariates from the entry year as controls. In the next section we look at export market performance, but we first verify whether there is sufficient identifying power in the relatively small sample of treated firms. Recall that we only compare new firms locating in a STIP or ETDZ with entrants locating outside these areas.

A major policy goal of the preferential areas is to facilitate the upgrading of domestic firms along the value chain and help them focus on higher value added activities. Success on this dimension could show up in productivity. In Table 1, we present the ATT estimates for labor productivity, capital intensity, and total factor productivity (TFP). ${ }^{11}$ Each statistic is estimated using a separate regression.

Firms locating in both types of preferential areas are found to operate at a much higher level of labor productivity than control firms. The difference is always positive and highly significant, even at the $1 \%$ level. The advantage for firms in a STIP is estimated at 0.206 or $0.214 \log$-points, depending on the estimation method. This implies a 22.9-23.9\% difference, controlling for location, sector, ownership, size, and wage rate. ${ }^{12}$ The productivity advantage is even slightly higher for firms locating in an ETDZ and it is already established 2 years into these firms' existence.

The estimates in the second column indicate that firms locating in these preferential areas employ vastly more capital. The estimated coefficients translate into enormous percentage differences with the capital intensity of control firms, averaging $44.3 \%$ for firms in STIPs and $87.3 \%$ in ETDZs over the two estimators. The sign is not surprising as access to capital is often a discretionary preferential policy in China, but the magnitude is remarkable.

We report TFP differences in the third column. For firms in STIPs we do not find any effect. Both point estimates are very close to zero and highly insignificant. Their labor productivity advantage is fully explained by the higher capital intensity, leaving no role for superior efficiency or technology. For firms in ETDZs, TFP is estimated slightly lower than for control firms, but barely significant. Their use of capital seems excessive and depresses their efficiency level. ${ }^{13}$

\footnotetext{
${ }^{11}$ Labor productivity is calculated as deflated value added per worker and TFP is calculated using a Törnqvist index, as in Brandt et al. (2012b).

12 A log-points difference of 0.206 implies a percentage difference of $\exp (0.206)-1=0.229$.

13 Another performance indicator we considered is the share of domestic value added in sales. An increase could signal a move away from simple assembly activities and to fewer imports of advanced parts. However, the estimates for this dependent variable were always close to zero and never significant (results available upon request).
} 
Table 1 Estimated ATT—productivity and capital intensity

\begin{tabular}{llll}
\hline Performance in year 2) & LP & K/L & TFP \\
\hline STIP & & & \\
Regression adjustment & 0.206 & 0.395 & -0.010 \\
& $(0.057)^{* * *}$ & $(0.064)^{* * *}$ & $(0.051)$ \\
Double robust & 0.214 & 0.338 & -0.009 \\
& $(0.057)^{* * *}$ & $(0.065)^{* * *}$ & $(0.053)$ \\
ETDZ & & & \\
Regression adjustment & 0.271 & 0.622 & -0.083 \\
& $(0.062)^{* * *}$ & $(0.063)^{* * *}$ & $(0.051)^{*}$ \\
Double robust & 0.257 & 0.593 & -0.074 \\
& $(0.048)^{* * *}$ & $(0.063)^{* * *}$ & $(0.079)$ \\
\hline
\end{tabular}

Statistics in parentheses are standard errors, obtained by 1,000 bootstrap replications for the double robust estimates

* Significance at the level of $10 \%$

*** Significance at the level of $1 \%$

Even though we only observe 458 entrants in STIPs and 891 entrants in ETDZs, the differences in Table 1 are estimated rather precisely. We conclude that firms locating in the preferential policy areas operate at much higher labor productivity, but this advantage is fully accounted for by their higher capital intensity, with no role for efficiency or technological differences. The supportive policy environment in the preferential zones seems to facilitate these firms' access to capital markets.

\subsection{Total export value and relative prices}

We now turn to export performance as an objective indicator of quality upgrading by domestic firms. This is in the spirit of the model in Sutton (2007) where success in the export market requires firms to achieve a minimum level of quality. In this section we focus on two measures of export performance: the total value of exports and the relative price obtained on the export markets (both measured in logarithms). Results in Table 2 are again for the ATT estimates and we now show performance differences 2 and 3 years after entry.

The difference in total export value with the group of control firms is always positive and statistically significant in six of the eight cases. For both types of preferential areas the four point estimates are estimated very consistently. For the STIPs they average 0.269 which implies $31 \%$ more exports by the average firm. The effect is stable over time and across the two estimation methods. Only the standard errors increase with the double robust estimation, which is expected, but an advantage of this method is its robustness to misspecification of the functional form.

For the ETDZs the estimates are almost as high, but only statistically significant using the unweighted regression adjustment estimator. The average across the four point estimates suggests an export volume that is $26 \%$ higher than for control firms-a 0.234 log-points difference. Using the double robust estimator the 
Table 2 Estimated ATT-export values and prices

\begin{tabular}{|c|c|c|c|c|}
\hline & \multicolumn{2}{|c|}{ Total export value } & \multicolumn{2}{|c|}{ Relative price } \\
\hline & Year 2 & Year 3 & Year 2 & Year 3 \\
\hline \multicolumn{5}{|l|}{ STIP } \\
\hline Regression adj. & $\begin{array}{l}0.269 \\
(0.094) * * *\end{array}$ & $\begin{array}{l}0.266 \\
(0.097)^{* * *}\end{array}$ & $\begin{array}{l}0.347 \\
(0.049) * * *\end{array}$ & $\begin{array}{l}0.392 \\
(0.082)^{* * *}\end{array}$ \\
\hline Double robust & $\begin{array}{l}0.278 \\
(0.162)^{*}\end{array}$ & $\begin{array}{l}0.262 \\
(0.139)^{*}\end{array}$ & $\begin{array}{l}0.405 \\
(0.101) * * *\end{array}$ & $\begin{array}{l}0.375 \\
(0.113)^{* * *}\end{array}$ \\
\hline \multicolumn{5}{|l|}{ ETDZ } \\
\hline Regression adj. & $\begin{array}{l}0.234 \\
(0.069)^{* * *}\end{array}$ & $\begin{array}{l}0.247 \\
(0.074) * * *\end{array}$ & $\begin{array}{l}0.008 \\
(0.036)\end{array}$ & $\begin{array}{l}0.018 \\
(0.042)\end{array}$ \\
\hline Double robust & $\begin{array}{l}0.238 \\
(0.146)\end{array}$ & $\begin{array}{l}0.216 \\
(0.156)\end{array}$ & $\begin{array}{l}0.018 \\
(0.061)\end{array}$ & $\begin{array}{l}-0.018 \\
(0.071)\end{array}$ \\
\hline
\end{tabular}

Statistics in parentheses are standard errors, obtained by 1,000 bootstrap replications for the double robust estimates

* Significance at the level of $10 \%$

*** Significance at the level of $1 \%$

estimates are not significantly different from zero and not very stable either. We deleted one outlier observation that received an extraordinary large weight and had a very negative impact on the ATT. Excluding sectors where FDI is officially prohibited or restricted, the estimates are more stable and range from 0.209 to 0.240 .

The evidence on the raw export performance for firms in STIPs and ETDZs is quite strong, persistent from year two to three, and robust over the two estimators. We now verify whether price differences can explain some of the gap. Evidence in Hallak (2006) illustrates that export price premiums are strong indicators of higher product quality. In the last two columns of Table 2 we report results in the same format, but using the normalized unit value ratios as dependent variable.

For STIPs, the price premiums are even higher than the total export advantage. These firms are able to charge much higher prices for their exports than firms in the control group. Recall that these prices have been normalized by the median unit value ratio for the detailed product category across all firms. All four point estimates are positive, often very large, and significant at the $1 \%$ level. There is no noticeable time trend in the data and the two estimators produce very consistent results. The average point estimate of 0.380 implies a price premium of $46 \%$.

The results for the firms in ETDZs provide a sharp contrast. While their performance in total export value is almost as strong as for firms in a STIP, they are not at all able to charge higher export prices than firms in the control group. Three of the four point estimates are positive, but none is even remotely significant and they are all very small in absolute magnitude. Using the alternative unit value ratios that are normalized by product-destination categories to filter out the impact of varying destinations, the point estimates rise, but only to 0.057 and 0.066 for the regression adjustment and to 0.071 and 0.000 for the double robust estimator. Even 
these premiums are relatively small and not significant even at the $10 \%$ level. On a sample of ETDZ firms that excludes multinationals, the point estimates even turn negative if we do not control for destinations.

The results suggest that firms locating in either type of preferential zone manage to export a lot more than firms locating on the outside. For STIPs, the higher foreign sales are explained entirely by higher prices. Easy access to capital and locating in the proximity of other high performing firms seems to generate large benefits in terms of product quality or identifying eager buyers. In contrast, the higher export sales of firms in ETDZs are driven almost exclusively by higher quantities. They seem to follow a strategy of mass production at high capital intensity with much less attention to quality.

To give these results a causal interpretation, the observations need to satisfy the unconfoundedness and overlap assumptions. The latter implies that the support of the conditional distribution of $\mathbf{x}$ given $w=0$ overlaps completely with that of the conditional distribution of $\mathbf{x}$ given $w=1$. Imbens and Wooldridge (2009) propose to verify this by calculating the population equivalent of the normalized differences:

$$
\frac{E(\bar{x} \mid w=1)-E(\bar{x} \mid w=0)}{\sqrt{V(x \mid w=1)+V(x \mid w=0)}} .
$$

For only 4 of the 46 variables in $\mathbf{x}$ does the absolute value exceed 0.25 , the threshold were Imbens and Rubin the authors suggest some concern. For only a single variable is the normalized difference higher than one, namely for the indicator variable whether there is another park in the same city. This variable was included to allow the treatment effect to vary with the economic environment in the region, not to control for potential self-selection.

The above test suggests that the linear specification in (3) provides an adequate fit for the data. A more stringent test to verify the overlap across the full range of the sample-which is necessary in our model as we do not match treatment and control firms explicitly_is suggested in Becker and Ichino (2002) and implemented in the pscore routine for Stata. The algorithm partitions the sample into groups of firms with similar propensity scores and tests for equality of the mean of the covariates in each sub-sample (block). We report the p-values of the tests for all variables in all blocks in Table 7 in the Appendix. Only 3 of the 228 tests suggest a rejection of equality of the covariate mean.

\subsection{Export destinations}

The next set of results in Table 3 explores whether treated firms also differ in the number and type of export destinations they serve. This provides additional information on the export strategy followed. In the first two columns, we report results for the (log) number of export destinations as performance variable.

For firms in a STIP, none of the coefficients is now statistically significant, not even for the estimator without weighing. We already established that their superior export sales was driven by prices, not by differences at the intensive margin (no evidence of higher quantity). We now find that they also do not differ on the 
Table 3 Estimated ATT-destination-specific export measures

\begin{tabular}{|c|c|c|c|c|}
\hline & \multicolumn{2}{|c|}{ No. of destinations } & \multicolumn{2}{|c|}{ Share high-income } \\
\hline & Year 2 & Year 3 & Year 2 & Year 3 \\
\hline \multicolumn{5}{|l|}{ STIP } \\
\hline Regression adj. & $\begin{array}{l}0.040 \\
(0.049)\end{array}$ & $\begin{array}{l}0.083 \\
(0.056)\end{array}$ & $\begin{array}{l}0.026 \\
(0.015)^{*}\end{array}$ & $\begin{array}{l}0.049 \\
(0.025)^{* *}\end{array}$ \\
\hline Double robust & $\begin{array}{l}0.043 \\
(0.076)\end{array}$ & $\begin{array}{l}-0.039 \\
(0.091)\end{array}$ & $\begin{array}{l}0.041 \\
(0.022)^{*}\end{array}$ & $\begin{array}{l}0.010 \\
(0.024)\end{array}$ \\
\hline \multicolumn{5}{|l|}{ ETDZ } \\
\hline Regression adj. & $\begin{array}{l}0.077 \\
(0.036)^{* *}\end{array}$ & $\begin{array}{l}0.053 \\
(0.043)\end{array}$ & $\begin{array}{l}0.005 \\
(0.011)\end{array}$ & $\begin{array}{l}0.040 \\
(0.020)^{* *}\end{array}$ \\
\hline Double robust & $\begin{array}{l}-0.060 \\
(0.079)\end{array}$ & $\begin{array}{l}0.035 \\
(0.083)\end{array}$ & $\begin{array}{l}0.003 \\
(0.021)\end{array}$ & $\begin{array}{l}-0.002 \\
(0.025)\end{array}$ \\
\hline \multicolumn{5}{|l|}{ ETDZ (no MNE) } \\
\hline Regression adj. & $\begin{array}{l}0.015 \\
(0.092)\end{array}$ & $\begin{array}{l}0.203 \\
(0.075)^{* * *}\end{array}$ & $\begin{array}{l}0.023 \\
(0.020)\end{array}$ & $\begin{array}{l}0.029 \\
(0.034)\end{array}$ \\
\hline Double robust & $\begin{array}{l}0.010 \\
(0.091)\end{array}$ & $\begin{array}{l}0.194 \\
(0.116)^{*}\end{array}$ & $\begin{array}{l}0.039 \\
(0.027)\end{array}$ & $\begin{array}{l}0.027 \\
(0.034)\end{array}$ \\
\hline
\end{tabular}

Statistics in parentheses are standard errors, obtained by 1,000 bootstrap replications for the double robust estimates

* Significance at the level of $10 \%$

** Significance at the level of $5 \%$

*** Significance at the level of $1 \%$

extensive margin (no evidence of more destinations). ${ }^{14}$ These results do not change if we limit the sample to domestic firms or exclude sectors where FDI is restricted.

For firms in an ETDZ, the point estimate for the second year using the regression adjustment is positive and significant at the $5 \%$ level. It suggests that these firms export to $8 \%$ more destinations than control firms. The other point estimates do not confirm this difference. The values are lower and standard errors higher.

However, performing the same regressions on the limited sample of domestic firms produces an interesting pattern. In the second year there is no difference at all, but the ATT effects are estimated much higher in year three. It is plausible that it takes time for firms to expand into new markets, especially for firms without the benefit of foreign owners. The absolute magnitude of the effect is also rather large: by the third year, domestic firms that locate in an ETDZ are estimated to serve 21-22\% more destinations.

The final performance measure is intended to capture quality indirectly by measuring the success of exporting to wealthier and more demanding marketswhich tend to have a higher willingness to pay for quality (Hallak 2006). The

\footnotetext{
${ }^{14}$ We did not investigate the extensive product margin as comparisons across firms of the total number of products exported are greatly influenced by the idiosyncracies of the HS classification.
} 
Table 4 High-tech firms in STIPs

\begin{tabular}{llllll}
\hline (Year 2) & $\begin{array}{l}\text { Export } \\
\text { value }\end{array}$ & $\begin{array}{l}\text { Relative } \\
\text { price }\end{array}$ & $\begin{array}{l}\text { Rel. price by } \\
\text { dest. }\end{array}$ & $\begin{array}{l}\text { No. of } \\
\text { destinations }\end{array}$ & $\begin{array}{l}\text { Share of } \\
\text { high-income }\end{array}$ \\
\hline Regression adj. & 0.540 & 0.490 & 0.575 & -0.028 & 0.035 \\
& $(0.213)^{* * *}$ & $(0.144)^{* * *}$ & $(0.157)^{* * *}$ & $(0.102)$ & $(0.033)$ \\
Double robust & 0.456 & 0.407 & 0.453 & 0.042 & 0.046 \\
& $(0.204)^{* *}$ & $(0.145)^{* * *}$ & $(0.175)^{* * *}$ & $(0.103)$ & $(0.029)$ \\
\hline
\end{tabular}

Statistics in parentheses are standard errors, obtained by 1,000 bootstrap replications for the double robust estimates

** Significance at the level of $5 \%$

*** Significance at the level of $1 \%$

dependent variable is the share of the total export value that is sold in high-income countries. Firms in STIPs are performing rather well in this respect. Most of the point estimates are positive and statistically significant. The opposing trends from year two to year three for the two estimators leave indeterminate whether firms have this advantage from the start or whether they learn from their neighbors, as in Swenson (2008). The average difference with the control group is estimated at $3.2 \%$. These results are consistent with the evidence that firms in STIP also charge higher prices.

The estimates are only slightly lower for domestic firms in ETDZs, but they are estimated less precisely and never significant. The uniformity of all four estimates and the comparable magnitude, 3.0 versus $3.2 \%$ for STIPs, provides some weak evidence of quality gains. Across all firms in the ETDZs, there is one large and significant estimate of 0.040 . It makes sense that multinationals have an easier time selling in high-income countries than domestic Chinese firms, but it is not necessarily tied to any upgrading trajectory. ${ }^{15}$

\subsection{Additional evidence: high-tech firms and ATE estimates}

So far, we have documented a large positive effect of locating in a STIP that is driven by an export price premium and to some extent by a larger share of exports going to high-income destinations. In Table 4 we revisit these results for the subsample of firms from the "Machinery and electronic equipment" industries (CIC industry codes 35-41). These firms are natural candidates to locate in a STIP and they produce goods for which China has a revealed comparative advantage.

The effects on total export values and relative prices are even larger than in the full sample and always significant at the $1 \%$ level. If we control for the composition of export destinations and normalize the relative prices not only by product but by the median price for each product-destination pair, the estimated price effect is even larger. They now correspond to a price premium of $78 \%$ for the regression

\footnotetext{
${ }^{15}$ We performed the same analysis with the high-income share measured by number of transactions. It leads to qualitatively similar estimates, but significance levels were often lower.
} 
adjustment estimator and $57 \%$ for the double robust estimator. These robust results are in spite of the number of treated firms being only half as large and the control group now consisting of better performing and more similar firms. It makes it more plausible that a causal interpretation of the results is warranted.

It is well known that most electronics exports from China to the West are of the export processing variety and only contain limited Chinese value added. The remaining results in Table 4 reveal that in spite of their elevated prices, electronics firms in STIPs do not focus specifically on high-income destinations nor do they serve more markets. The higher price effects obtained when conditioning on destination even suggests that their price premiums are higher in lower-income destinations, at least relative to other Chinese exporters. This makes it unlikely that the positive results are merely an indication of export processing activities.

For firms in ETDZs, the effect on total export value was almost as large as for firms in STIPs. In this case higher prices explained very little, but there was some evidence that these firms served a wider range of export destinations. Because any firm is eligible to set up in an ETDZ, it is informative to also calculate the ATE estimates for a wider sample and not only the effect on treated firms. These estimates measure what the predicted effect would be for a random firm, taking into account that it might differ in characteristics from the typical firm in an ETDZ.

We perform these calculations specifically for the group of domestic firmsprivate, collective, or state-owned-as policymakers are likely to be most interested in their upgrading trajectory. The ATT and ATE estimates are reported in Table 5 for all performance dimensions. We only report double robust estimates, results are similar and even more significant for the regression adjustment estimator.

The potential effects on the full population of domestic firms turn out to be very different from the average effect on firms that actually located in an ETDZ. The strong effect on total exports disappear and the large effect on the number of destinations in year 3 that we previously reported also does not hold up. In contrast, while treated firms did not show higher relative prices and only a weak effect on the share of exports going to high-income countries, these 'quality' measures turn out large and significant if we average them over the full population.

Table 5 Domestic firms in ETDZs: ATE and ATT (double robust) estimates

\begin{tabular}{llllll}
\hline (Year 2) & Export value & No. of dest. (year 3) & Relative price & Rel. price by dest. & $\begin{array}{l}\text { Share of } \\
\text { high-income }\end{array}$ \\
\hline \multirow{2}{*}{ ATT } & 0.216 & 0.194 & -0.077 & 0.039 & 0.039 \\
& $(0.207)$ & $(0.116)^{*}$ & $(0.080)$ & $(0.098)$ & $(0.027)$ \\
ATE & -0.016 & -0.053 & 0.272 & 0.391 & 0.071 \\
& $(0.220)$ & $(0.142)$ & $(0.127)^{* *}$ & $(0.146)^{* * *}$ & $(0.035)^{* *}$ \\
\hline
\end{tabular}

Statistics in parentheses are standard errors, obtained by 1,000 bootstrap replications for the double robust estimates

* Significance at the level of $10 \%$

** Significance at the level of $5 \%$

*** Significance at the level of $1 \%$ 
Note that the differences between the ATT and ATE estimates are driven entirely by differences in the mean covariates between the treated firms and the population at large. The exact same conditional treatment effects-conditioning on the full set of covariates in $\mathbf{x}$-are used in both calculations. The conditional effects are always constructed by comparing similar firms within and outside the ETDZs, but different weights are used when aggregating them to the respective averages. The starkly different patterns for ATT and ATE in Table 5 have two causes: (1) estimated treatment effects vary greatly across firms with different covariates, and (2) the average firm locating in an ETDZ differs systematically from the average firm in the full sample.

In particular, firms that actually located in ETDZs are more likely to be the type of firm that benefit on the quantity dimension (total export value and number of destinations), but not on the quality dimension. In contrast, firms within the ETDZs that are most similar to the average firm on the outside did obtain higher export prices than observationally similar firms on the outside. Similarly, the ATE estimate for the share of exports going to high-income countries is almost double the ATT estimate. It implies that firm characteristics that are positively correlated with a high conditional treatment effect for the two quality dimensions are on average higher for firms outside than inside ETDZs.

The takeaway from the results in Table 5 is that firms locating in an ETDZ are no random group. Hence, it is important to control for potential self-selection, as we have done. It also suggests that if different firms were encouraged to locate in the ETDZs, the overall effects could be quite different. For the dimensions of export quality (relative price and share of high-income), the ATE estimates for ETDZs are even similar to the ATT effects for STIPs, where only selected firms are permitted. Allowing any firm to locate in a preferential area seems to be able to boost the quantity of exports, but it is not conducive to raise export quality.

\section{Conclusion}

We have analyzed the effectiveness of Science and Technology Industrial Parks and Economic and Technology Development Zones to stimulate an upgrading process for China's manufacturing firms. Treated firms are new entrants that locate in these preferential policy areas and benefit from tax reductions, duty exemptions, state-ofthe-art infrastructure, etc. For firms locating in a STIP there is the additional benefit of locating near other high-tech firms that are screened by the park authorities. The control group consists of observationally similar entrants that start up on the outside.

We use a unique data set that matches transaction-level trade statistics to information on firm characteristics. It permits us to identify treatment at the firm level and construct dependent variables that capture multiple dimensions of export performance. Success on the export market is arguably a more objective gauge of firm-upgrading or quality than input measures such as R\&D or FDI. As we can follow firms over time we can compare performance 2 and 3 years after entry, while controlling for size, wages, ownership type, location, and industry. 
The results indicate that treated firms operate with a lot more capital than untreated firms, which raises labor productivity substantially, but without a noticeable effect on TFP. Most importantly, export market performance is strongly enhanced for firms locating in both types of preferential areas. The patterns on different dimensions of performance suggest that firms locating in ETDZs and STIPs follow a different export strategy.

Total export values are higher for firms in ETDZs which comes almost entirely from higher quantities with only a very small role for price premiums. We find a positive effect on the total number of export destinations, especially for domestic firms, but this only appears in the third year. The firms only very weakly outperform the control group in selling exports to high-income countries. In all, it suggests that firms in ETDZs follow a strategy of mass producing goods in a capital-intensive way. They compete effectively on price, which leads to large quantities sold in many overseas market. It is a successful strategy, but not one of upgrading along the value chain. The average treatment effect estimated for the full population, not just for treated firms, suggests that the lack of selectivity attracts this type of firms, while the few firms in the ETDZs that are more alike the average firm on the outside did experience quality improvements.

Firms locating in a STIP show more success in upgrading. They also display much higher total export values, but this is now driven entirely by higher export prices. They show no effect on the total number of destinations, but the share of exports going to high-income countries is significantly higher. The value and price effects are even more pronounced for firms in STIPs that produce machinery, even though their control group of outside firms is a lot stronger as well. Controlling for the composition of export destinations, the price premium they fetch on the export market is even higher, suggesting that these firms are particularly competitive in lower-income countries (where prices tend to be lower). Together these patterns can be interpreted as indirect evidence of quality upgrading.

Acknowledgments We would like to thank participants at the sixth ISGEP workshop, the ICTNET workshop in Mannheim, the CO-REACH conference in Maastricht, the ARC conference in Louvain, as well as two anonymous referees for comments. Funding by the E.U.'s ERC Program and KU Leuven Program Financing is gratefully acknowledged. 


\section{Appendix}

See Tables 6 and 7.

Table 6 Summary statistics by treatment status

\begin{tabular}{|c|c|c|c|}
\hline & Control firms & STIP & ETDZ \\
\hline Number of observations & 14,110 & 458 & 891 \\
\hline Fraction in "Machinery and electronics" & 0.281 & 0.598 & 0.380 \\
\hline \multicolumn{4}{|l|}{ Average export performance } \\
\hline Total export value (in mio. USD) & 5.87 & 10.81 & 11.49 \\
\hline No. of destination countries & 6.95 & 7.42 & 7.02 \\
\hline Fraction high-income destinations & 0.774 & 0.780 & 0.804 \\
\hline Fraction high-income exports & 0.781 & 0.798 & 0.815 \\
\hline Relative price (relative to median $=1$ ) & 0.97 & 1.35 & 1.08 \\
\hline Relative price by destination $($ med. $=1$ ) & 1.00 & 1.29 & 1.03 \\
\hline \multicolumn{4}{|l|}{ Locations } \\
\hline Yangtze River Delta (Shanghai) & 0.442 & 0.485 & 0.332 \\
\hline Pearl River Delta (Guangdong) & 0.289 & 0.118 & 0.144 \\
\hline Yellow River Delta (Beijing) & 0.208 & 0.317 & 0.442 \\
\hline Central region & 0.039 & 0.038 & 0.051 \\
\hline Western region & 0.022 & 0.042 & 0.031 \\
\hline \multicolumn{4}{|l|}{ Firm size } \\
\hline Small ( $<50$ employees) & 0.157 & 0.214 & 0.206 \\
\hline Medium (51-250 employees) & 0.590 & 0.524 & 0.550 \\
\hline Large (250+ employees) & 0.253 & 0.262 & 0.224 \\
\hline \multicolumn{4}{|l|}{ Ownership categories } \\
\hline State-owned & 0.077 & 0.104 & 0.053 \\
\hline Collectives & 0.012 & 0.009 & 0.005 \\
\hline Private & 0.204 & 0.085 & 0.065 \\
\hline Hong Kong, Macau, Taiwan & 0.316 & 0.221 & 0.219 \\
\hline Foreign & 0.279 & 0.581 & 0.658 \\
\hline \multicolumn{4}{|l|}{ Wage rate per employee } \\
\hline Average, relative to sample average & 0.956 & 1.690 & 1.339 \\
\hline Median, relative to sample median & 0.980 & 1.631 & 1.251 \\
\hline
\end{tabular}

Sample is first year following entry for firms entering between 1999 and 2005 
Table $7 \quad P$-values for tests whether the balancing property is satisfied

\begin{tabular}{|c|c|c|c|c|c|c|c|}
\hline Block & 1 & 2 & 3 & 4 & 5 & 6 & 7 \\
\hline pis & 0.337 & 0.048 & 0.020 & 0.784 & 0.177 & 0.046 & 0.510 \\
\hline lognwwpw & 0.651 & 0.869 & 0.638 & 0.190 & 0.025 & 0.243 & 0.522 \\
\hline logsize & 0.670 & 0.486 & 0.001 & 0.377 & 0.577 & 0.486 & 0.452 \\
\hline ownership_2 & 0.023 & 0.616 & 0.450 & 0.564 & 0.262 & 0.686 & - \\
\hline ownership_3 & 0.230 & 0.940 & 0.568 & 0.643 & 0.043 & 0.531 & - \\
\hline ownership_4 & 0.665 & 0.235 & 0.101 & 0.436 & 0.418 & 0.832 & 0.634 \\
\hline ownership_5 & 0.561 & 0.068 & 0.056 & 0.304 & 0.176 & 0.623 & 0.548 \\
\hline yellow & 0.662 & 0.517 & 0.169 & 0.262 & 0.790 & 0.102 & 0.474 \\
\hline yangtze & 0.813 & 0.226 & 0.251 & 0.241 & 0.577 & 0.028 & 0.685 \\
\hline pearl & 0.868 & 0.734 & 0.563 & 0.847 & 0.712 & 0.567 & - \\
\hline ci2_1 & 0.278 & 0.352 & 0.552 & 0.524 & - & 0.686 & 0.820 \\
\hline ci2_2 & 0.596 & 0.523 & 0.984 & 0.801 & 0.627 & 0.686 & - \\
\hline ci2_3 & 0.835 & 0.780 & 0.577 & 0.468 & 0.779 & - & - \\
\hline ci2_4 & 0.116 & 0.691 & 0.932 & 0.401 & 0.691 & - & 0.744 \\
\hline ci2_5 & 0.241 & 0.504 & 0.553 & 0.567 & 0.691 & 0.567 & - \\
\hline ci2_6 & 0.385 & 0.844 & . & 0.848 & 0.779 & - & - \\
\hline ci2_7 & 0.885 & 0.525 & 0.815 & 0.848 & - & - & - \\
\hline ci2_8 & 0.495 & 0.403 & 0.496 & 0.074 & 0.378 & - & - \\
\hline ci2_9 & 0.904 & 0.685 & 0.715 & 0.841 & 0.553 & 0.014 & - \\
\hline ci2_11 & 0.829 & 0.537 & 0.396 & 0.668 & - & - & - \\
\hline ci2_13 & 0.835 & 0.509 & 0.764 & 0.086 & 0.302 & 0.630 & 0.820 \\
\hline ci2_14 & 0.957 & 0.860 & 0.253 & 0.535 & 0.726 & 0.282 & - \\
\hline ci2_15 & 0.940 & 0.708 & 0.354 & 0.947 & 0.530 & 0.686 & - \\
\hline ci2_16 & 0.815 & 0.584 & 0.983 & 0.641 & 0.924 & - & 0.820 \\
\hline ci2_17 & 0.639 & 0.035 & 0.700 & 0.044 & 0.051 & 0.417 & 0.820 \\
\hline ci2_18 & 0.801 & 0.458 & 0.250 & 0.997 & 0.574 & 0.753 & - \\
\hline ci2_19 & 0.743 & 0.616 & 0.545 & 0.047 & - & - & - \\
\hline ci2_20 & 0.852 & 0.716 & 0.200 & 0.522 & 0.150 & 0.482 & - \\
\hline ci2_21 & 0.392 & 0.644 & 0.180 & 0.337 & 0.982 & 0.686 & 0.820 \\
\hline ci2_22 & 0.865 & 0.685 & 0.269 & 0.330 & 0.816 & 0.347 & 0.820 \\
\hline ci2_23 & 0.915 & 0.760 & 0.755 & 0.555 & 0.928 & 0.295 & 0.634 \\
\hline ci2_24 & 0.904 & 0.218 & 0.472 & 0.513 & 0.641 & 0.084 & - \\
\hline ci2_25 & 0.957 & 0.732 & 0.740 & 0.435 & 0.263 & 0.528 & 0.820 \\
\hline ci2_26 & 0.940 & 0.678 & 0.218 & 0.007 & 0.140 & 0.316 & 0.302 \\
\hline ci2_27 & 0.915 & 0.791 & 0.308 & 0.206 & 0.935 & 0.913 & 0.798 \\
\hline ci2_28 & 0.001 & 0.364 & 0.570 & 0.396 & 0.794 & 0.567 & - \\
\hline ci2_29 & 0.542 & 0.690 & 0.230 & 0.018 & 0.779 & - & 0.744 \\
\hline
\end{tabular}

Statistics are $p$-values for a test whether a covariate has the same mean for treated and control firms within a partitioning of the sample by propensity score (in columns). Italics cells indicate a rejection of equality 


\section{References}

Arkolakis, C. (2010). Market penetration costs and the new consumers margin in international trade. Journal of Political Economy, 118(6), 1151-1199.

Becker, S. O., \& Ichino, A. (2002). Estimation of average treatment effects based on propensity scores. The Stata Journal, 2(4), 358-377.

Bernard, A. B., \& Jensen, J. B. (1995). Exporters, jobs, and wages in U.S. manufacturing, 1976-1987. Brookings Papers on Economic Activity. Microeconomics, 1995, 67-119.

Bernard, A. B., Jensen, J. B., Redding, S. J., \& Schott, P. K. (2007). Firms in international trade. Journal of Economic Perspectives, 21(3), 105-130.

Brandt, L., Van Biesebroeck, J., Wang, L., \& Zhang, Y. (2012a). WTO accession and firm-level productivity in Chinese manufacturing. (CEPR Discussion Paper 9166). London: Centre for Economic Policy Research.

Brandt, L., Van Biesebroeck, J., \& Zhang, Y. (2012b). Creative accounting or creative destruction? Firmlevel productivity growth in Chinese manufacturing. Journal of the Development Economics, 97(2), 339-351.

Démurger, S., Sachs, J. D., Woo, W. T., Bao, S., Chang, G., \& Mellinger, A. (2002). Geography, economic policy, and regional development in China. Asian Economic Papers, 1(1), 146-197.

Fan, P., \& Watanabe, C. (2006). Promoting industrial development through technology policy: Lessons from Japan and China. Technology in Society, 28(3), 303-320.

Greenstone, M., Hornbeck, R., \& Moretti, E. (2010). Identifying agglomeration spillovers: Evidence from winners and losers of large plant openings. Journal of Political Economy, 118(3), 536-598.

Hallak, J. C. (2006). Product quality and the direction of trade. Journal of International Economics, 68(1), 238-265.

Head, K., \& Ries, J. (1996). Inter-city competition for foreign investment: Static and dynamic effects of China's incentive areas. Journal of Urban Economics, 40(1), 38-60.

Hirano, K., Imbens, G. W., \& Ridder, G. (2003). Efficient estimation of average treatment effects using the estimated propensity score. Econometrica, 71(4), 1161-1189.

Hu, A. G. (2007). Technology parks and regional economic growth in China. Research Policy, 36(1), $76-87$.

Hu, A. G. Z., \& Jefferson, G. H. (2008). Science and technology in China. In L. Brandt, T. G. Rawski (Eds.), China's great economic transformation, Chapter 9 (pp. 286-336). Cambridge: Cambridge University Press.

Hu, X. (2005). A study of sustainable development of China's state-level Economic and Technological Development Zones. China \& World Economy, 13(3), 92-106.

Hussinger, K. (2008). R\&D and subsidies at the firm level: An application of parametric and semiparametric two-step selection models. Journal of Applied Econometrics, 23(6), 729-747.

Imbens, G., \& Wooldridge, J. (2009). Recent developments in the econometrics of program evaluation. Journal of Economic Literature, 47(1), 5-86.

Inkpen, A. C., \& Wang, P. (2006). An examination of collaboration and knowledge transfer: ChinaSingapore Suzhou industrial park. Journal of Management Studies, 43(4), 779-811.

Liu, B. J., \& Wu, Y.-Y. (2011). Development zones in China: Are STIPs a substitute for or a complement to ETDZs? Taipei Economic Inquiry, 47(1), 97-145.

Macdonald, S., \& Deng, Y. (2004). Science parks in China: A cautionary exploration. International Journal of Technology Intelligence and Planning, 1(1), 1-14.

Manova, K., \& Zhang, Z. (2012). Export prices across firms and destinations. Quarterly Journal of Economics, 127(1), 379-436.

Ministry of Science and Technology. (2011). Torch high technology industry development center: Mission. http://168.160.159.69/english/.

Roberts, M., \& Tybout, J. (1997). The decision to export in Colombia: An empirical model of entry with sunk costs. American Economic Review, 87(4), 545-564.

Robins, J. M., Rotnitzky, A., \& Zhao, L. P. (1995). Analysis of semiparametric regression models for repeated outcomes in the presence of missing data. Journal of the American Statistical Association, 90(429), 106-121.

Saxenian, A. (2002). The Silicon Valley connection: Transnational networks and regional development in Taiwan, China and India. Science Technology \& Society, 7(1), 117-149. 
Sutton, J. (2007). Quality, trade and the moving window: The globalisation process. Economic Journal, 117(524), 469-498.

Swenson, D. L. (2008). Multinationals and the creation of Chinese trade linkages. Canadian Journal of Economics, 41(2), 596-618.

Van Biesebroeck, J., Yu, E., \& Chen, S. (2011). The impact of trade promotion services on Canadian exporter performance. (CEPR Discussion Paper 8597). London: Centre for Economic Policy Research.

Wagner, J. (2007). Exports and productivity: A survey of the evidence from firm-level data. World Economy, 30(1), 60-82.

Walcott, S. (2003). Chinese science and technology industrial parks. Aldershot: Ashgate Publishing Ltd.

Wooldridge, J. (2010). Econometric analysis of cross section and panel data (2nd ed.). Cambridge and London: MIT Press.

World Bank. (2011). Country and lending groups. http://data.worldbank.org/about/country-classifications/ country-and-lending-groups.

Zhang, H., T. Sonobe (2011). Development of Science and Technology Parks in China, 1988-2008. Economics: The Open-Access, Open-Assessment E-Journal 5 (2011-6). http://dx.doi.org/10.5018/ economics-ejournal.ja.2011-6 